\title{
Maternal Complications of Caesarean Section in a Resource-Limited Country: The Case of the Maternity Unit of Kankan Regional Hospital, Guinea
}

\author{
Mamadou Hady Diallo1*, Ibrahima Sory Baldé2, Amadou Diouldé Diallo³, Ousmane Baldé1, \\ Boubacar Siddi Diallo', Ibrahima Sylla², Oumou Hawa Bah'1, Lanciné Doumbouya4, \\ Aisssatou Taran Diallo5, Yolande Hyjazi'1, Namory Keita ${ }^{1}$
}

${ }^{1}$ University Department of Gynecology-Obstetrics, Donka National Hospital, Conakry, Guinea

${ }^{2}$ University Department of Gynecology-Obstetrics, Ignace Deen National Hospital, Conakry, Guinea

${ }^{3}$ University Department of Visceral Surgery, Donka National Hospital, Conakry, Guinea

${ }^{4}$ Maternity Unit, Kankan Regional Hospital, Kankan, Guinea

${ }^{5}$ University Department of Visceral Surgery, Ignace Deen National Hospital, Conakry, Guinea

Email: *hadydiallo2002@yahoo.fr

How to cite this paper: Diallo, M.H., Baldé, I.S., Diallo, A.D., Baldé, O., Diallo, B.S., Sylla, I., Bah, O.H., Doumbouya, L., Diallo, A.T., Hyjazi, Y. and Keita, N. (2019) Maternal Complications of Caesarean Section in a Resource-Limited Country: The Case of the Maternity Unit of Kankan Regional Hospital, Guinea. Open Journal of Obstetrics and Gynecology, 9, 981-990. https://doi.org/10.4236/ojog.2019.97095

Received: May 12, 2019

Accepted: July 15, 2019

Published: July 18, 2019

Copyright (๑) 2019 by author(s) and Scientific Research Publishing Inc. This work is licensed under the Creative Commons Attribution International License (CC BY 4.0).

http://creativecommons.org/licenses/by/4.0/

\section{cC) (7) Open Access}

\begin{abstract}
Introduction: Innovations in surgical and anaesthetic techniques to provide a good maternal and child safety have made the cesarean section a routine intervention in obstetrics. However, its complications, especially the short or long term per and postoperative maternal ones, are not exceptional and can affect mothers' vital prognosis. The objectives of this study were to describe the maternal per and postoperative complications encountered during the cesarean section. Patients and method: This is a prospective, descriptive and analytical study carried out at the maternity ward of Kankan Regional Hospital over a 6 month period from January 1, 2018 to June 30, 2018. Results: During this period, out of a total of 2229 deliveries, 319 caesarean sections were performed i.e. a rate of $12.51 \%$. Complications concerned 111 patients (34.79\%). The average age was 28 with extremes of 15 and 45 . Non-medical transportation concerned $71.17 \%$ of our patients. The cesarean section was performed in emergency situations in $82.8 \%$ of cases. Indications were dominated by the fetopelvic disproportion. There was a statistically significant relationship between labour duration and the occurrence of complications. Intraoperative complications were dominated by bleeding $(25.22 \%$ of all complications and $8.77 \%$ of total cesarean sections). Post-operative complications were dominated by parietal suppurations (94.49\% of all complications and $34.79 \%$ of the total number of cesarean sections). In most cases, patients
\end{abstract}


simultaneously developed several complications. Conclusion: The maternal complications of cesarean sections remain considerable. If the increase in the rate of caesarean sections has contributed to the improvement of the mother-fetal prognosis, the surgical procedure itself is not without complications, which encourages us to review its indications for a better management. Hemorrhagic and infectious complications were the most frequent. These results call for increased asepsis measures in our operation theaters to reduce infectious complications. The increase in Caesarean section rates over the years is faced with increased maternal morbidity in the short and long term. Its indications should be well thought out and should include the responsibility of an experienced obstetrician.

\section{Keywords}

Complications, Cesarean, Maternity, Kankan-Guinea

\section{Introduction}

Caesarean section is one of the most common surgical procedures performed in obstetrics and is certainly one of the oldest surgical procedures [1] [2]. Its incidence is increasing worldwide [3] [4]. The WHO has stated that the caesarean section rate should ideally be between $10 \%$ and $15 \%$ [5]. In recent decades, the proportion of cesarean births has steadily increased in both developing and developed countries. Many factors contributed to the increase in the rate of Caesarean section worldwide, including improved surgical and anaesthetic techniques, reduced risk of short-term postoperative complications, and patients' perceptions of the safety of the procedure [5] [6] [7].

The incidence of the cesarean section varies from one country to another and from one hospital to another within a country [8].

Over the last 30 years, the incidence of cesarean section has increased from 5 to about $25 \%$ or even over $50 \%$ in some countries [8].

Risks and safety associated with Caesarean section delivery differ from one place to another around the world [9]. Despite huge advances in obstetrical technology and anaesthesia to provide better maternal safety during cesarean sections, rates of maternal complications remain high, sometimes jeopardizing patients' vital prognosis and obstetrical outcomes.

In Africa some authors have reported the incidence of maternal complications of cesarean sections which varies from $10.3 \%$ in a Moroccan study to $40.55 \%$ in a Guinean study [10] [11].

The high frequency of post-caesarean maternal complications and the lack of previous studies at this centre motivated this work, which was carried out with the following objectives in mind:

1) to determine the frequency of maternal complications of cesarean sections;

2) to describe the socio-demographic characteristics of patients concerned;

3) to identify factors associated with maternal complications of cesarean sec- 
tions;

4) to describe the nature of maternal complications of cesarean sections.

\section{Patients and Method}

We conducted a prospective, descriptive and analytical study over a 6-month period from January 1, 2018 to June 30, 2018.

Inclusion criteria: All women admitted and hospitalized for maternal complications related to a cesarean section at Kankan Regional Hospital.

Exclusion criteria: We excluded all cesareanized women with simple consequences, women who developed a nosocomial infection outside the surgical site, at the uterus and its appendices.

\section{Collect Data and Analyze}

This was an exhaustive sampling of all women who had undergone a cesarean section surgery. Data were collected as soon as the patients arrived. Support documents used were the survey form and the obstetrical file. For each patient we studied the socio-demographic such as age, occupation, source, marital status, level of education, parity, clinical such as reasons for consultation, history of caesarean section, indications for cesarean section, context of cesarean delivery, factors associated with maternal complications of caesarean section, intraoperative maternal complications, postoperative maternal complications and prognostic characteristics (favorable, unfavorable and fatal evolution).

The results were expressed as a percentage and as an average in a table form. The comparison between the different variables was made using the Paerson Chi-square and the observed differences were considered significant when $\mathrm{P}$ is lower than or equal to 0.05 .

Limitations and difficulties: The results can only be applied to the study site. The socio-economic level of the women evacuated and the high cost of additional examinations have been established.

\section{Results}

\subsection{Frequencies}

Out of a total of 2229 deliveries, we recorded 319 cases of cesarean sections, i.e. a rate of $12.51 \%$. Maternal complications concerned 111 patients, representing a frequency of $34.79 \%$ for all Caesarean sections.

\subsection{Socio-Demographic Characteristics}

1) Age: Complications occurred in all age groups. The 15 - 24 age group was the most affected with a frequency of $39.6 \%$. The average age of our patients was 28 with extremes of 15 and 45 years.

2) Occupation: In our study we noted a predominance of housewives with a rate of $89.1 \%$.

3) Place of origin: Most of the patients in our study resided in rural areas 
$(61.26 \%)$ compared to $38.73 \%$ in urban areas.

4) Marital status: The majority of women were married i.e. $99.09 \%$.

5) Educational level: The majority of patients did not attend school, i.e. $89.18 \%$.

6) Parity: The average parity was 4.2 with extremes of 1 and 11 . First-time mothers were the most affected (32.6\%).

7) Patients transportation mode: In the majority of cases, transportation was not medicalized i.e. $83.78 \%$ versus $16.22 \%$ of medicalized transportation.

\subsection{Clinical Characteristics}

1) Reasons for consultation: Uterine contractions and prolonged labour were the most common reasons for consultation i.e. $82.8 \%$ and $73.8 \%$ respectively.

2) History of the caesarean section: Most of the patients who developed complications had no history of cesarean section (69.3\%), 21.6\% had a single scar uterus, $7.2 \%$ had a bi scar and $1.8 \%$ had a tri scar.

3) Indications for the caesarean section: Indications are summarized in $\mathrm{Ta}$ ble 1 .

They were dominated by fetopelvic disproportion followed by the scarred uterus.

4) Context in which the caesarean section was performed: $82.8 \%$ of the caesarean sections were performed in an emergency setting. They were programmed in $17.2 \%$.

5) Factors associated with maternal complications of cesarean sections. These factors are summarized in Table 2.

Table 1. Indications for Caesarean section.

\begin{tabular}{ccc}
\hline Indications for Caesarean section & & \\
\hline Fetal-pelvic disproportion & 37 & 33.33 \\
Uterine pre-breakup syndrome & 10 & 9 \\
Labor failure & 1 & 11.7 \\
Retroplacental hematoma & 13 & 8.1 \\
Placenta previa & 9 & 1.8 \\
Dystocic presentation & 2 & 2.7 \\
Fetal death in utero & 3 & 17.1 \\
Scar uterus & 19 & 10.8 \\
Acute fetal suffering & 12 & 17.1 \\
\hline Other & & 4.5 \\
\hline Uterine rupture & 52 & 82.9 \\
\hline Caesarean section context & 19 & \\
\hline Emergency & 92 & \\
\hline
\end{tabular}


Table 2. Factors associated with surgical complications of cesarean section. Fisher.

\begin{tabular}{|c|c|c|c|}
\hline Variables & $\begin{array}{c}\text { With } \\
\text { complications } \\
\mathrm{N}=111\end{array}$ & $\begin{array}{c}\text { Without } \\
\text { complications } \\
\mathrm{N}=208\end{array}$ & P-value \\
\hline Labour duration in hours & & & $<0.001$ \\
\hline$<12 \mathrm{~h}$ & $36(21.7)$ & $130(78.3)$ & \\
\hline$\geq 12 \mathrm{~h}$ & $75(49.0)$ & $78(51.0)$ & \\
\hline The rupture time of the membr & anes & & $<0.001$ \\
\hline Intact & $33(54.1)$ & $28(45.9)$ & \\
\hline Membrane failure & $78(30.2)$ & $180(69.8)$ & 0.752 \\
\hline $\begin{array}{l}\text { The duration of work was greater than or } \\
\text { equal to } 12 \text { hours in } 49 \% \text { of parturients. There } \\
\text { was a statistically significant relationship } \\
\text { between the duration of labor and the } \\
\text { complications of cesarean section ( } \mathrm{P} \text { less than } \\
0.001) \text {. We found } 85.7 \% \text { of complications in } \\
\text { patients with a membrane rupture duration } \\
\text { greater than } 12 \text { hours. There is a statistically } \\
\text { significant relationship between the duration } \\
\text { of the rupture and the maternal complications } \\
\text { of caesarean section }(\mathrm{P}=0.001)\end{array}$ & & & \\
\hline
\end{tabular}

6) Peroperative maternal complications are summarized in Table 3 : Haemorrhage was the most common perioperative complication $25.22 \%$ of all complications and $8.77 \%$ of all caesarean sections.

7) Post-operative complications are summarized in Table 4: In most cases, patients simultaneously developed several complications.

Postoperative complications were dominated by parietal suppuration $95.49 \%$ compared to all complications and $34.79 \%$ compared to all cesarean sections.

8) Maternal lethality: The trend was favorable in $98.75 \%$ of cases. We recorded 4 maternal deaths, i.e. a lethality rate of $1.25 \%$.

\section{Discussion}

\subsection{Frequencies}

We found that the frequency of maternal complications of cesarean sections is very high in our series: $34.79 \%$. Ngowa et al. reported a $16.95 \%$ complication rate in a study conducted in 2 university hospitals in Yaoundé [12]. However, our rates are lower than those reported by Diallo F B et al. at the Ignace Deen Maternity Hospital in Conakry Guinea where the incidence of complications was $40.55 \%$ [11]. It should be noted that maternal complications in this Guinean hospital were dominated by infection, which accounted for $71 \%$ of all complications. The lower incidence of postoperative infection in this study would be the consequence of an improvement in the level of the technical platform. However, it remains high, which could be explained by the evacuation, the prolonged labor, the high frequency of the premature rupture of membranes and the performance 
Table 3. Peroperative maternal complications.

\begin{tabular}{cccc}
\hline $\begin{array}{c}\text { Perioperative } \\
\text { complications }\end{array}$ & Number of people & $\begin{array}{c}\text { \% in relation to } \\
\text { complications }\end{array}$ & $\begin{array}{c}\text { \% of total cesarean } \\
\text { section }\end{array}$ \\
\hline $\begin{array}{c}\text { Perioperative } \\
\text { hemorrhage }\end{array}$ & 28 & 25.22 & 8.77 \\
Bladder wound & 16 & 14.41 & 5.01 \\
Bladder wound & 3 & 2.7 & 0.94 \\
Digestive wound & 2 & 1.8 & 0.62 \\
Total & & & \\
\hline
\end{tabular}

Table 4. Peroperative maternal complications.

\begin{tabular}{cccc}
\hline $\begin{array}{c}\text { Post-operative } \\
\text { complications }\end{array}$ & Number of people & $\begin{array}{c}\text { \% in relation to } \\
\text { complications }\end{array}$ & $\begin{array}{c}\text { \% of total cesarean } \\
\text { sections }\end{array}$ \\
\hline Parietal Suppuration & 106 & 95.49 & 34.79 \\
Postpartum hemorrhage & 14 & 12.61 & 4.38 \\
Postpartum endometritis & 12 & $33.22 \%$ & 3.76 \\
Urinary infection & 11 & 9.9 & 3.44 \\
Thrombophlebitis & 7 & 6.3 & 2.19 \\
Eventration/Evisceration & 6 & 5.4 & 1.88 \\
Pelviperitonitis & 3 & 2.7 & 0.94 \\
\hline
\end{tabular}

of the cesarean section in an emergency setting.

\subsection{Perioperative Complications}

In our series $35.12 \%$ of complications were perioperative.

The perioperative bleeding was the most frequent complication, and affected $8.77 \%$ of our patients. This rate is well above the $3.6 \%$ reported by Trabelski $\mathrm{K}$ et al. [13] and the $4.9 \%$ reported by Benkirane $S$ et al. [14]; it is close to that reported by Dupont C et al. (7.1\%) [15]. This incidence is differently assessed d depending on the definition adopted and the time of occurrence. These hemorrhages may be due to general factors such as coagulation and hemostasis disorders or local factors of placental, uterine origin or secondary factors due to traumatic lesions [16] [17]. The causes of bleeding were dominated by uterine inertia. Uterine atonies were found more frequently for emergency Caesarean sections than for scheduled Caesarean sections $(45.48 \%$ versus $11.22 \%, \mathrm{P}<0.05)$.

Hemorrhagic complications were more frequent during the perioperative period, but they also occurred in the post-operative period, requiring prolonged hospitalization, blood transfusions or even surgical resumption.

In our series, 3 patients had a bladder wound, representing $0.94 \%$ of all cesarean sections, and all 3 wounds occurred following an emergency cesarean section for scarring of the uterus on pelvic anomalies. There were also 2 cases of digestive wounds, i.e. a rate of $0.62 \%$, which also occurred following a caesarean section performed on the uterus with multiple adherences. Benkirane et al. re- 
ported in their study a rate of $0.62 \%$ bladder wound and $0.12 \%$ of digestive wound [14]. Digestive wounds and bladder wounds are among the least frequent perioperative complications during cesarean sections. In our series, intubation difficulties were reported in 8 cases without incident, representing $2.5 \%$ of all cesarean sections. This complication was observed in $0.33 \%$ of the Hawthorne study [18]. A case of Mendelson's syndrome was found in our study, representing $0.31 \%$ of all cesarean sections, and this complication resulted in the patient's death. Mendelson's syndrome is a rare but fearsome complication [18]. Some prophylactic measures could reduce the incidence of this syndrome, observing 6 to 8-hour fasting time before the caesarean section, buffering of the gastric contents before the emergency caesarean section [18]. The cesarean section anaesthesia is the leading cause of maternal anaesthetic mortality ( $84 \%$ in the USA) [18]. General anaesthesia is the most frequently incriminated cause $(69.9 \%$ of cases). Ventilation problems are responsible for death in $73 \%$ of cases, about equally divided between gastric inhalation and intubation difficulties [19].

\subsection{Post-Operative Complications}

In our series, infectious complications were at the first rank of post-operative complications of cesarean sections, largely dominated by parietal suppuration, which affected $34.79 \%$ of all cesarean sections; this is followed by endometritis $3.76 \%$. Benkirane S et al. reported a rate of $10.4 \%$ of cesarean sections with infectious complications, and its risk factors were represented primarily by the urgency of the cesarean section and the rupture of the water pocket [14]. Women who deliver by cesarean section are 5 to 20 times more likely to become infected than women who deliver vaginally [20]. These complications lead to significant postnatal morbidity, prolonging the duration of hospitalization and significantly increasing the financial cost. Their incidences vary from $7 \%$ to $25 \%$ depending on the authors and can vary widely depending on the criteria used [21]. Wall infections are the contamination of the scar by bacteria of skin or vaginal origin. It should be noted that many studies have shown that less than half of surgical site infections are diagnosed before the patient leaves the maternity ward. The overall incidence is therefore particularly underestimated if they are not sought after the patient's discharge [22]. Concerning endometritis, their incidence is assessed in different ways by authors. For Benkirane et al. it was 2\% [14].

In our study, postpartum hemorrhage involved 14 patients, i.e. a rate of $4.38 \%$. In the study reported by Ngowa et al. [12] these hemorrhagic complications occurred in $8.48 \%$ of patients.

In our series 11 patients developed a urinary infection i.e. $3.44 \%$. This is underestimated due to the lack of a systematic related research. Van Ham [23] reported a frequency of $3 \% .7$ cases of thrombophlebitis of the lower limb i.e. a rate of $2.19 \%$ were recorded. Early morning wake up was systematic. However, low molecular weight heparin was not available. Risk factors were mainly represented by: advanced age, the lack of patient follow-up and the urgent context of the cesarean section. Clément reported a frequency of 0.34 and identified 
multiparity, obesity, thromboembolic history, prolonged bed rest, hemostasis disorders and infection as the main risk factors [24]. There were also 6 event cases i.e. a rate of $1.88 \%$. This rate is higher than the one reported by Benkirane $S$ [14]. These 6 cases were surgically resumed and the postoperative outcomes were without anomalies.

3 cases of pelviperitonitis were recorded i.e. a rate of $0.94 \%$, which were surgically repeated and the consequences were good. Benkirane $\mathrm{S}$ et al. reported $0.21 \%[14]$.

\subsection{Maternal Lethality}

We recorded 4 maternal deaths, representing a lethality of $1.25 \%$. This high rate would be explained by the weakness of the technical platform.

Maternal mortality after caesarean sections is no longer the one we observed a long time ago, thanks to advances in resuscitation, anaesthesia, antibiotic therapy and blood transfusion techniques. In the Moroccan study, maternal mortality after caesarean sections was 2.8 per 1000, which is 3 times higher than the risk of vaginal delivery [10]. It was $1.4 \%$ in the Cissé et al. study in Senegal and 3.45\% in a study in Guinea [11] [25]. It is known that caesarean sections are associated with a much higher risk of maternal death than vaginal deliveries [26].

\section{Conclusions}

From the results of this study it appears that maternal complications of cesarean sections remain considerable. Infectious and hemorrhagic complications were the most frequent.

These results call for increased perioperative asepsis measures in our surgical theaters to reduce infectious complications. Greater awareness among health personnel of the need of a better preparation for childbirth at the end of pregnancy will reduce the frequency of patient's transfers from birthing centers and health centers to hospital. The continuous increase in caesarean section rate over the years collides with increased maternal morbidity in the short and long term. Indications for cesarean sections should be well thought out and include the responsibility of an experienced obstetrician.

\section{Conflicts of Interest}

The authors declare no conflicts of interest regarding the publication of this paper.

\section{References}

[1] World Health Organization (1985) Appropriate Technology for Birth. The Lancet, 326, 436-437. https://doi.org/10.1016/S0140-6736(85)92750-3

[2] Kwawukume, E.Y. (2002) Caesarean Section in Comprehensive Obstetrics in the Tropics. Asante and Hittscher Printing Press, Accra, 321-329.

[3] Nwosu, C., Agumor, K., Aboyeji, A.P. and Ijaiya, M.A. (2004) Outcome of Cesarean Section in a Sub-Urban Secondary Health Care Facility in Nigeria. The Nigerian 
Medical Practitioner, 46, 77-79. https://doi.org/10.4314/nmp.v46i4.28733

[4] Stanton, C.K., Sara, A. and Holtz, S.A. (2006) Levels and Trends in Cesarean Birth in the Developing World. Studies in Family Planning, 37, 41-48.

https://doi.org/10.1111/j.1728-4465.2006.00082.x

[5] OMS (2016) WHO Statement on Caesarean Section Rates. WHO/RHR, 8(1845), $02-15$.

[6] Bertran, A.P., et al. (2016) What Is the Optimal Rate of Caesarean Section at Population Level? A Systematic Review of Ecologic Studies. Reproductive Health, 10, $15-43$.

[7] HAS (2016) Indications of Caesarean Section Scheduled in the Long Term.

[8] Marc, H. (2007) Operative Delivery. In: Alan, H.D. and Lauren, N., Eds., Current Obstetrics and Gynecological Diagnosis and Treatment, 10th Edition, McGraw Hill Publishers, New York, 469-476.

[9] Villar, J., Valladares, E., Wojdyla, D., Zavaleta, N., Carroli, G., Velazco, A., Shah, A., et al. (2006) Caesarean Delivery Rates and Pregnancy Outcomes: The 2005 WHO Global Survey on Maternal and Perinatal Health in Latin American. The Lancet, 367, 1819-1829. https://doi.org/10.1016/S0140-6736(06)68704-7

[10] Hassan, A., Abderrahim, A., Fadila, M., Noureddine, M., Amine, H. and El Mansouri, A. (2001) Maternal Complications of Caesarean Sections: Retrospective Analysis of 3231 Interventions at the University Maternity Hospital in Casablanca, Morocco. French-Speaking Study and Research Notebooks. Santé, 10, 419-423.

[11] Diallo, F.B., Diallo, M.S., Bangoura, S., Diallo, A.B. and Camara, Y. (1998) Caesarean Section: A Factor in Reducing Morbidity and Fetomaternal Mortality at Ignace Deen University Hospital in Conakry, Guinea. Médecine d'Afrique Noire, 45, 359-364.

[12] Ngowa, J.D.K., Ngassam, A., Fouogue, J.T., Metogo, J., Medou, A. and Kasia, J.M. (2015) Early Maternal Complications of Caesarean Section: About 460 Cases in Two Yaoundé University Hospitals, Cameroun. Pan African Medical Journal, 21, 265

[13] Trabelsi, K., Jedidi, J., Yaich, S., Louati, D., Amouri, H., Gargouri, A., Damak, J. and Guermazi, M. (2006) Preoperative Maternal Complications of Caesarean Section: About 1404 Cases. 33-38.

[14] Benkirane, S., Saadi, H. and Mimouni, A. (2017) The Epidemiological Profile of Maternal Complications of Cesarean Section at CHR El Farabi Oujda. Pan African Medical Journal, 27, 108. https://doi.org/10.11604/pamj.2017.27.108.10036

[15] Dupont, C., Rudigoz, R.C., Cortet, M., et al. (2014) Frequency, Causes and Risk Factors of Postpartum Heamorrhage: A Population Based Study in 106 French Maternity Units. Journal de Gynécologie Obstétrique et Biologie de la Reproduction (Paris), 43, 244-253. https://doi.org/10.1016/j.jgyn.2013.05.003

[16] Suwal, A., Shrivastava, V.R. and Giri, A. (2013) Maternal and Fetal Outcome in Elective versus Emergency Cesarean Section. Journal of Nepal Medical Association, 52, 563-566. https://doi.org/10.31729/jnma.2426

[17] Fomulu, J.N., Tiyou, K.C., Mbu, R.E., Nana, N.P. and Leke, R.J.I. (2008) Maternal Mortality at the Main Maternity Hospital in Yaoundé: Retrospective Study from 2001 to 2006. Health Sciences and Diseases, 9, 86-92.

[18] Arvieux, C.C., Rossignol, B. and Gueret, G. (2001) Anesthesia for Emergency Cesarean Section. 9-25.

[19] Abbassi, H., Aboulfalah, A., Morsad, F., Matar, N., Himmi, A. and Mansouri, A.E. (2000) Maternal Complications of Caesarean Sections: Retrospective Analysis of 
3231 Interventions in Casablanca. Sante, 10, 419-423.

[20] Smaill, F.M. and Grivell, R.M. (2014) Antibiotic Prophylaxis versus No Prophylaxis for Preventing Infection after Cesarean Section. Cochrane Database of Systematic Reviews, No. 10, CD007482. https://doi.org/10.1002/14651858.CD007482.pub3

[21] Audra, P. (1990) Infectious and Hemorrhagic Complications of Cesarean Section, about 2200 Procedures. Rev Fr Gynecol Obstet., 85, 111-113.

[22] Graver-Tropper, D.C., et al. (1995) Underestimation of Surgical Site Infection Rates in Obstetrics and Gynecology. American Journal of Infection Control, 23, 22-26. https://doi.org/10.1016/0196-6553(95)90004-7

[23] Van Ham, M.A., Van Dongen, P.W. and Mulder, J. (1997) Maternal Consequences of Cesarean Section, a Retrospective Study of Intraoperative and Post-Operative Maternal Complications of Cesarean Section during a 10 Year Period. European Journal of Obstetrics \& Gynecology and Reproductive Biology, 74, 1-6. https://doi.org/10.1016/S0301-2115(97)02725-5

[24] Clement, H., Caffin, J.P. and Corty, C. (1990) Prevention of Thromboembolic Complications after Caesarean Section. Rev Fr Gynecol Obstet., 85, 114-117.

[25] Cissé, C.T., Andriamady, C., Faye, O., Diouf, A., Bouillin, D. and Diadhiou, F. (1995) Indications and Prognosis of Cesarean Section Surgery at Dakar University Hospital. Journal of Gynaecology-Obstetrics and Reproductive Biology, 24, 194-197.

[26] Deneux-Tharaux, C., Carmona, E., Bouvier-Colle, M.H. and Bréart, G. (2006) Postpartum Maternal Mortality and Cesarean Delivery. Obstetrics \& Gynecology, 108, 541-548. https://doi.org/10.1097/01.AOG.0000233154.62729.24 